\title{
Renal transplantatıon and morbid obesity
}

\author{
Zerrin Ozcelik* \\ Intensive Care Unit Sihhiye, Hacettepe University Medical School, Ankara,Turkey
}

Obesity is a worldwide epidemic and public health crisis associated with severe comorbidity leading to end organ dysfunction and poorer transplant outcome [1].

The most common method for defining obesity is based on BMI (i.e., a person's weight [kilograms] divided by the square of his or her height [meters]). The World Health Organization (WHO) considers a BMI between 20 and $25 \mathrm{~kg} / \mathrm{m}^{2}$ as normal weight, a BMI between 25 and $30 \mathrm{~kg} / \mathrm{m}^{2}$ as overweight, and a BMI of $30 \mathrm{~kg} /{ }^{2}$ as obese. The National Institutes of Health defined morbid obesity as aBMI $\geq 35 \mathrm{~kg} / \mathrm{m}^{2}$ and severe, obesity related comorbidity as a BMI $\geq 40 \mathrm{~kg} / \mathrm{m}^{2}$ [2].

Although BMI is easy to calculate and used in many nutritional guidelines, this metric is a poor estimate of fat mass distribution, especially in chronic kidney disease(CKD) which may not be able to differentiate visceral adiposity from muscle mass and non-visceral fat mass. Although waist-hip ratio(WHR)and skin fold thickness are superior to BMI for the correct classification of obesity in CKD in cross-sectional studies, WHR may not be a valid estimate of changes in visceral fat mass over time[3-6].

There areso many comorbid conditions associated with severe obesity that include insulin resistance,diabetes mellitus,increased abdominal fat raises the intra-abdominal pressure and contributes to gastroesophageal reflux, stress urinary incontinence, venous stasis disease, and abdominal hernia in obese patients. Fatty deposits in the liver can progress to nonalcoholic steatohepatitisand excess weight causes joint and back stress that can lead to debilitating joint disease.

Obese patients have impaired pulmonary function, particularly decreased functional residual capacity, and frequently suffer from asthma, obstructive sleep apnea, and obesity hypoventilation syndrome (chronic hypoxemia, hypercarbia, pulmonary hypertension, and polycythemia; Pickwickian syndrome). Other comorbidities include hypertension, dyslipidemia, asthma, and sex hormone dysfunction. Obesity is associated with an increased incidence of uterine, breast, ovarian, prostate, and colon cancer, and of skin infections, urinary tract infections, migraine headaches, depression, and pseudotumor cerebri. The low-grade inflammatory state associated with morbid obesity has been implicated in the development of vascular and coronary artery disease and the hypercoagulable state seen in these patients $[7,8]$.

The American Society of Transplantation recommend a supervised weight loss regimen including a low-calorie diet, behavioral therapy, and a physical activity plan to achieve a goal body mass index (BMI) of less than 30 prior to kidney transplantationand also note that there are insufficient data to suggest which obese patients should be denied a transplant based on their obesity [9].

An analysis of 188 patients Modanlou et al., included patients undergoing weight-reduction surgery both prior to listing and after transplantation demonstrated a 30 -day mortality of $3.5 \%$ with a further
$3.5 \%$ dying at 90 days in the post-transplant group [10].

'Obesity paradox' has long been recognized in dialysis with a higher BMI being associated with animproved survival [11].

This phenomenon may be due to the association between sarcopenia (reduced muscle mass) and low BMI. Schold et al., demonstrated that weight loss after transplant listing had no positive impact on posttransplant mortality or graft loss irrespective of BMI at the time of listing [12].

Taken together, the observational data suggest that both a lower $\mathrm{BMI}$ and weight loss associated with sarcopenia predicts poor outcomes on dialysis[12].

Obesity impacts many inter-related considerations for transplant practice including candidate selection, outcomes prediction before and after transplant, and waitlist management.

Obese patients transplantation candidates should undergo a thorough cardiac, pulmonary, endocrine and nutritional counselingto minimize medical and surgical complications and improve survival and quality of life[13].

Compared to recipients with $\mathrm{BMI} \leq 30$, those with obesity defined by BMI $>30$ had longer operative times, prolonged hospitalizations, higher rates of reintubation, more frequent intensive care unit admissions, and a greater incidence of wound complications[14].

Wound infection is the most common issue encountered in the perioperative period.Decreased oxygen tension and ischemia at the suture line, presence of chronic skin fold infections, and generalized immune impairment, even prior to the immunosuppression medications can lead to this issue[15,16]. Renal transplantation in obese patients has increased risk of surgery including anesthetic problems of airway control and venous access problems, impaired preoperative lung function in approximately one third of obese patients, an increase in cardiac stroke work leading to circulatory problems, thromboembolic,wound complications andtechnical considerations including hemostatic problems andanatomotic function [17-19]. There are also logistical issues such as blood pressure cuff sizing, ultrasound assistance for procedures, diminished quality of some imaging modalities, and capabilities of hospital equipment such as beds and lifts are important considerations [20].

The pulmonary function of obese patients is altered by mechanical

Correspondence to: Zerrin Ozcelik, Intensive Care Unit Sihhiye, Hacettepe University Medical School, Ankara,Turkey, E-mail: zeeerrinozcelik@hotmail.com

Received: November 10, 2016; Accepted: November 25, 2016; Published: November 28, 2016 
disability, leading to smaller lung volumes and decreased chest wall compliance[21]. The lack of pain medication can lead to rapid shallow breathing and atelectasis. Incentive spirometry, and continuous positive airway pressure (CPAP) can be used to prevent atelectasis and pneumonia. For thromboembolic risk, anticoagulation with heparin and/or vena caval filters be placed preoperatively in the highest risk patients[21,22].

Outcome differences in obese renal transplant patients were primarily due to a higher mortality resulting from cardiac events. Modlin et al., also stated that, obese patient with a history of cardiac disease should not be transplanted until weight reduction $<30 \mathrm{~kg} / \mathrm{m}^{2}$ [23].

Predisposition to ventricular hypertrophy and increases in blood volume should be considered in fluid management decisions[20]. Sodium intakes are individualized based on fluid retention and blood pressure[24].

Following transplantation, many patients exhibit hypophosphatemia and mild hypercalcemia caused by bone resorption; this is associated with persistent hyperparathyroidism and the effects of steroids on calcium, phosphorous and vitamin D metabolism. Fluid and electrolyte requirements should be evaluated daily. Typically, patients are encouraged to drink $2 \mathrm{~L}$ /day, but their overall needs depend on their urine output [25].

Nutritional management of transplant patients will be determined by nutritional status, immunosuppression regimen, presence of infection, function of the transplanted graft, other organ functions, wound healing and metabolic and surgical complications.

Obesity directly impacts transplant outcomes. Meier- Kriesche et al., have shown that patient and graft survival are lower in obese patients $(\mathrm{BMI}>30)$. They indicated that, it is specifically related to wound infection and breakdown and is greater when the BMI is $>30[26,27]$.

Whether or not obesity impacts early graft function or long-term outcomes remains unclear.In Yamomoto's study 28 pairs of kidneys were transplanted; one in an obese patient while the other was placed into a nonobese recipient. Graft survival, including delayed graft function, was noted to be similar in the short term but statistically worse for the obese cohort at 7 years and they stated thatchronic allograft nephropathy (CAN) was the primary culprit, rather than cardiovascular factors [28]. Obese patients are considered for transplant because of the obvious survival benefit as compared to the wait listed dialysis patients, despite the poorer outcomes [29].

The number of obese persons is increasing in Turkey[30,31]. In Gurkan et al., studyalthough the complication rate was found to be higher in obese renal transplanted group compared with non obese, the patient and graft survival rates were similar. And the annual mortality rate of obese transplant patients was lower than the annual mortality rate of average dialysis patients reported by the Turkish Society of Nephrology[32].

Grosso et al., retrospectively reviewed 376 renal transplant recipients to evaluate graft and patient survivals between normal and over weight and obese patients at the time of transplantation. Graft loss and was significantly higher and survival was significantly loweramong obese compared with non obese recipients. They indicated that careful patient selection with pretransplantation weight loss is mandatory to reduce the rate of early posttransplantation complications and to improve long term outcomes[33].
ButKandoum et al.'s retrospective study, they showed a significant risk of surgical complications after renal transplantation but they suggested thisnot affect graft survivalbecause any renal transplanted patient needtransplantectomy or return to dialysis[34].

The weight-loss surgery in the kidney disease population is unclear[35].Freeman et al., presented a prospective evaluation of laparoscopic sleeve gastrectomy(LSG) for patients failing to achieve significant weight loss with medical therapy.Over a 25 month period, 52 obese renal transplant candidates with an average preoperative BMI of $43.0 \pm 5.4 \mathrm{~kg} / \mathrm{m}^{2}$ underwent LSG. They suggested that LSG is safe, efficaous and superior to medical weight loss management and can increase access to transplantation[36].

Golomb et al., performed8 patients LSG, afterrenal transplantation. The median preoperative BMI $42 \mathrm{~kg} / \mathrm{m}^{2}[37]$.They suggested LSG provided effective weight loss in renal transplant patients without adverse effects on graft function and immunosuppression[37].

Immunosuppression therapy is known to induce metabolic adverse effects, such as protein hypercatabolism, hyperlipidemia, glucose intolerance, hyperkalemia, hypophosphatemia, hypomagnesemia. The nutritional status after transplant is also determined by preexisting medical conditions, such as protein losses, renal osteodystrophy, hyperlipidemia, and cardiovascular disease.

Patients with body mass index (BMI) $>30 \mathrm{~kg} / \mathrm{m}^{2}$ are at risk for steroid induced posttransplant diabetes mellitus[23]. For all renal transplant patients dietary advice should be individualized and include exercise plans and specific goals. The diet should be planned with a moderate energy restriction of about 30\% of energy expenditure to reduce body weight in overweight or obese kidney transplant recipients[26].

A combination of several immunosuppressive medications is needed in all transplant recipients to prevent acute andchronic rejection for long-term graft survival. Significant changes in the volume of distribution of drugs occur in obese patients, particularly for lipophilic drugs. When initially dosing lipophilic drugs, the dosages should be based on ideal body weight (IBW) and a percentage of the excess body weight. Altered concentration of plasma binding proteins, differences in regional blood flow, and variable body composition can affect tissue distrubution and transport of drugs into different tissue compartments so the drug doses are unpredictable[38].

Specific dose adjustments could not be made, but recommendations to closely monitor sirolimus and tacrolimus.Mycophenolic acid is metabolized in the gastrointestinal tract, kidney, and liver. Two peak concentration times can be seen when the drug is taken in combination with tacrolimus or sirolimus. The first peak is associated with absorption, whereas the second is thought to be due to enterohepatic circulation of the drug and its metabolites MPA levels can be monitored by area under the curve (AUC) estimation[38].

\section{Conclusion}

Obese patients are considered for transplant because of the obvious survival benefit as compared to the wait listed dialysis patients, despite the poorer outcomes[29].

The goal is to selectpatients who likely to have a good outcome. This can be achieved by a multidisciplinary team and a thorough pretransplant evaluation and optimization of the obese patientsmedical comorbidities. 


\section{References}

1. Killackey M, Zhang R, Sparks K, Paramesh A, Slakey D, et al. (2010) Challenges of abdominal organ transplant in obesity. South Med J 103: 532-540. [Crossref]

2. NIH conference (1991) Gastrointestinal surgery for severe obesity. Consensus Development Conference Panel. Ann Intern Med 115(12): 956-61.

3. WHO Expert Consultation (2004) Appropriate body-mass index for Asian populations and its implications for policy and intervention strategies. Lancet 363: 157-163. [Crossref]

4. Agarwal R, Bills JE, Light RP (2010) Diagnosing obesity by body mass index in chronic kidney disease: an explanation for the "obesity paradox?". Hypertension 56 : 893-900. [Crossref]

5. Zoccali C, Torino C, Tripepi G, Mallamaci F (2012) Assessment of obesity in chronic kidney disease: what is the best measure? Curr Opin Nephrol Hypertens 21: 641-646. [Crossref]

6. Velludo CM, Kamimura MA, Sanches FM, Lemos MM, Canziani ME, et al. (2010) Prospective evaluation of waist circumference and visceral adipose tissue in patients with chronic kidney disease. Am J Nephrol 31: 104-109. [Crossref]

7. Snow V, Barry P, Fitterman N, Qaseem A, Weiss K; Clinical Efficacy Assessment Subcommittee of the American College of Physicians (2005) Pharmacologic and surgical management of obesity in primary care: a clinical practice guideline from the American College of Physicians. Ann Intern Med 142: 525-531. [Crossref]

8. McTigue KM, Harris R, Hemphill B, Lux L, Sutton S, et al. (2003) Screening and interventions for obesity in adults: summary of the evidence for the U.S. Preventive Services Task Force. Ann Intern Med 139: 933-949. [Crossref]

9. Kasiske BL, Cangro CB, Hariharan S, Hricik DE, Kerman RH, et al. (2001) The evaluation of renal transplantation candidates: clinical practice guidelines. $\mathrm{Am} \mathrm{J}$ Transplant 1 Suppl 2: 3-95. [Crossref]

10. Modanlou KA, Muthyala U, Xiao H (2009) Bariatric surgery among kidney transplan candidates and recipients: analysis of the United States renal data system and literature review. Transplantation 87: 1167-1173.

11. Kalantar-Zadeh K, Streja E, Kovesdy CP (2010) The obesity paradox and mortality associated with surrogates of body size and muscle mass in patients receiving hemodialysis. Mayo Clin Proc 85: 991-1001

12. Schold JD, Srinivas TR, Guerra G, Reed AI, Johnson RJ, et al. (2007) A "weightlisting" paradox for candidates of renal transplantation? Am J Transplant 7: 550-559. [Crossref]

13. Ditonno P, Lucarelli G, Impedovo SV, Spilotros M, Grandaliano G, et al. (2011) Obesity in kidney transplantation affects renal function but not graft and patient survival. Transplant Proc 43: 367-372. [Crossref]

14. Lentine KL, Delos Santos R, Axelrod D, Schnitzler MA, Brennan DC, et al. (2012) Obesity and kidney transplant candidates: how big is too big for transplantation?. Am J Nephrol 36: 575-586. [Crossref]

15. DeMaria EJ, Carmody BJ (2005) Perioperative management of special populations: obesity. Surg Clin North Am 85: 1283-1289, xii. [Crossref]

16. Dindo D, Muller MK, Weber M, Clavien PA (2003) Obesity in general elective surgery. Lancet 361: 2032-2035. [Crossref]

17. Zhang R, Liao J, Morse S, Donelon S, Reisin E (2005) Kidney disease and the metabolic syndrome. Am J Med Sci 330: 319-325. [Crossref]

18. Kambham N, Markowitz GS, Valeri AM, Lin J, D’Agati VD (2001) Obesity-related glomerulopathy: an emerging epidemic. Kidney Int 59: 1498-1509. [Crossref]

19. Patel S, Pankewycz O, Kohli R, Said M, Alnimri M, et al. (2011) Obesity in renal transplantation: the role of induction therapy on long-term outcomes. Transplant Proc 43: 469-471. [Crossref]
20. Shashaty MG, Stapleton RD (2014) Physiological and management implications of obesity in critical illness. Ann Am Thorac Soc 11: 1286-1297. [Crossref]

21. Mathier MA, Ramanathan RC (2007) Impact of obesity and bariatric surgery on cardiovascular disease. Med Clin North Am 91: 415-431, x-xi. [Crossref]

22. Quan S, Gersh B. National Center of Sleep Disorders Research; National Heart, Lung and Blood Institute (2004) Cardiovascular consequences of sleep disordered breathing: past, present and future: report of a workshop from the National Center on Sleep Disorders Research and the National Heart, Lung and Blood Institute. Circulation 109: 951-957.

23. Howard RJ, Thai VB, Patton PR, Hemming AW, Reed AI, et al. (2002) Obesity does not portend a bad outcome for kidney transplant recipients. Transplantation 73: 53-55. [Crossref]

24. Qureshi AR, Lindholm B, Alvestrand A, Bergström J, Tollemar J, et al. (1994) Nutritional status, muscle composition and plasma and muscle free amino acids in renal transplant patients. Clin Nephrol 42: 237-245. [Crossref]

25. Bernardi A, Biasia F, Pati T, Piva M, D'Angelo A, Bucciante G (2003) Long-term protein intake control in kidney transplant recipients: effect in kidney graft function and in nutritional status. Am J Kidney Dis 41: S146eS152.

26. Kasiske BL, Vazquez MA, Harmon WE, Brown RS, Danovitch GM, et al. (2000) Recommendations for the outpatient surveillance of renal transplant recipients. American Society of Transplantation. J Am Soc Nephrol 11 Suppl 15: S1-86. [Crossref]

27. Meier-Kriesche H, Arndorfer J, Kaplan B (2002) The impact of body mass index on renal transplant outcomes: a significant independent risk factor for graft failure and patient death. Transplantation 73: $70-74$.

28. Modlin CS, Flechner SM, Goormastic M, Goldfarb DA, Papajcik D, et al. (1997) Should obese patients lose weight before receiving a kidney transplant? Transplantation 64 599-604. [Crossref]

29. Yamamoto S, Hanley E, Hahn AB, Isenberg A, Singh TP, et al. (2002) The impact of obesity in renal transplantation: an analysis of paired cadaver kidneys. Clin Transplant 16: 252-256. [Crossref]

30. Satman I, Yilmaz T, Sengül A, Salman S, Salman F, et al. (2002) Population-based study of diabetes and risk characteristics in Turkey: results of the turkish diabetes epidemiology study (TURDEP). Diabetes Care 25: 1551-1556. [Crossref]

31. CDC.www.cdc.gov/chronicdisease/resources/publications/aag/pdf/2010/AAG Obesity.2010.

32. Registry of the nephrology, dialysis and transplantation in Turkey 2008. Available from: http://www.tsn.org.tr/folders/file/registry (Last accessed on October 2011)

33. Grosso G, Corona D, Mistretta A, Zerbo D, Sinagra N, et al. (2012) The role of obesity in kidney transplantation outcome. Transplant Proc 44: 1864-1868. [Crossref]

34. Kamdoum Nanfack ML, Bayoud Y, Marchand C, Cholley I, Leon P, et al. (2015) [Is obesity a barrier to kidney transplantation?]. Prog Urol 25: 40-46. [Crossref]

35. Alexander JW, Goodman H (2007) Gastric bypass in chronic renal failure and rena transplant. Nutr Clin Pract 22: 16-21. [Crossref]

36. Freeman CM, Woodle ES (2015) Addressing Morbid Obesity as a Barrier to Rena Transplantation with Laparoscopic Sleeve Gastrectomy. Am J Transplant XX: 1-9

37. Golomb I, Winkler J (2014) Laparoscopic Sleeve Gastrectomy as a Weight Reduction Strategy in Obese Patients After Kidney Transplantation. Am J Transplant 14: 2384 2390

38. Rogers C, Alloway R, Alexander J (2008) Pharmacokinetics of mycophenolic acid tacrolimus and sirolimus after gastric bypass surgery in end-stage renal disease and transplant patients: a pilot study. Clin Transpl 22: 281-291.

Copyright: (C)2016 Ozcelik Z. This is an open-access article distributed under the terms of the Creative Commons Attribution License, which permits unrestricted use, distribution, and reproduction in any medium, provided the original author and source are credited. 